\title{
Impact of Financial Inclusion On Smes Growth: Channelizing New Approaches
}

\author{
Humera Tariq \\ Alumni: Hamad bin Khalifa University, Qatar \\ h_ipchem@yahoo.com
}

\begin{abstract}
Small and Medium Enterprises (SMEs) play a pivotal role in fostering economy by handling a considerable proportion in the commerce and creating job opportunities. However, potential of SMEs is untapped yet due to various factors. Among its constraints, unavailability of financial resources is a major barrier and access to finance augmented by financial inclusion (FI) is devised as relevant solution. Extant literature embodies a disunited proof on FI-SME growth nexus that clearly calls for certain new channels to be explored in this regard. Grounded upon endogenous growth perspective and resource-based view, this study endorses that growth is the outcome of internal resources and human capital is as important as financial or physical capital. An economy destitute of skills and education cannot efficiently utilize financial resources to generate economic activities. This conceptual paper reveals the relationship between financial inclusion, education and SMEs growth. Furthermore, this study adds value in existing literature by evaluating the necessary and relevant channels, videlicet, levels of education, skills, vocational training, innovation, and ease of business. Findings advocated that SMEs growth cannot be effective if lacking these trajectories. Spending on education, vocational and corporate trainings strengthen innovation that subsequently fosters SMEs development. This theoretical paper recommends suggestions for policy makers and it provides an agenda to researchers to enhance the knowledge by conducting empirical analysis on this topic.
\end{abstract}

Key words: Financial inclusion, Education, Innovation, Business Freedom, SMEs growth 